\title{
Moodle Öğrenme Yönetim Sistemi için Ethereum Blok Zinciri Tabanlı Belge Doğrulama Akıllı Sözleşmesinin Geliştirilmesi
}

\author{
Araştırma Makalesi/Research Article
}

\author{
Erinç KARATAŞ \\ Computer Technologies Department, Elmadag Vocational School, Ankara University, Ankara, Türkiye \\ ekaratas@ankara.edu.tr \\ (Geliş/Received:10.08.2018; Kabul/Accepted:23.10.2018) \\ DOI: $10.17671 /$ gazibtd. 452686
}

\begin{abstract}
$\ddot{O}_{z} \boldsymbol{e t}$ - Geleneksel eğitim anlayışında bireyler, anaokulundan liseye devam eden eğitimleri sonrasında isterlerse lisans hatta lisansüstü eğitim alma yolunu izlerler. Bugün bu klişenin dışına çıkarak, okuma yazma bilen her birey farklı öğrenme ortamlarını tercih edebilmektedir. Günümüz için herhangi bir konuyu öğrenmek, dört duvarı olan bir okul binasına, belli bir zaman dilimine bağlı kalmaya gerek olmaksızın bireylerin parmaklarının ucuna kadar gelmektedir. Bu çalışmada, Uluslararası Enformatik ve Bilgi İşlemsel Düşünme Etkinliğinin Türkiye ayağı kapsamında katılımcılara verilen Dijital Sertifikaların Ethereum Blok Zinciri temelli akıllı sözleșme kullanılarak doğrulanabilmesi hedeflenmiștir. Türkiye'de öğrencilere etkinlikteki görevler, Moodle Öğrenme Yönetim Sisteminin sınav modülü kullanılarak ulaştırılmaktadır. Bu çalışmanın amaçları doğrultusunda ilk olarak Ethereum blok zinciri üzerinde sertifika bilgilerinin saklanabileceği ve gerektiğinde kontrol amaçlı sorgulanabileceği bir akıllı sözleșme geliștirilmiş, daha sonra ise araștırmacı tarafindan 2014 yılında geliştirilen ve blok yapısı kullanılan Moodle Öğrenme Yönetim Sistemindeki sertifika modülü güncellenerek Ethereum blok zincirindeki akıllı sözleşme ile uyumlu çalışması sağlanmıştır.
\end{abstract}

\section{Developing Ethereum Blockchain-Based Document Verification Smart Contract for Moodle Learning Management System}

\begin{abstract}
In the traditional educational understanding, individuals follow the path of getting graduate or post-graduate education if they wish, after continuing their education from kindergarten to high school. Today, by getting out of this stereotype, every literate person can choose different learning environments. Now, learning any subject is up to the tip of the fingers of an individual without depending on a school building with four walls or on certain time frame. In this study, it is aimed to verify digital certificates given to the participants at the Turkish stage of the International Informatics and Computational Thinking event by using Ethereum Block Chain based smart contract. The tasks in the event were transmitted to the students in Turkey via using exam module of the Moodle Learning Management System. For this study, first a smart contract was developed in which the certificate information could be stored on the Ethereum blockchain and could be check for control purposes if necessary. Then the certificate module developed by the researcher in 2014 which uses block structure in the Moodle Learning Management System was updated and then provided to work in accordance with the smart contract in the Ethereum blockchain.
\end{abstract}

Keywords - Ethereum Blokchain, Smart Contract, Moodle Learning Management System, Document Verification 


\section{INTRODUCTION}

In the traditional educational understanding, individuals follow the path of getting graduate or post-graduate education if they wish, after continuing their education from kindergarten to high school. Today, by getting out of this stereotype, every literate person can choose different learning environments. In the traditional education system, many variables such as age, gender, previous educational experience, place of residence, and socio-economic situation can be an obstacle for the individual to benefit from formal education; however with the reflections of technology on education, today there are many possibilities for spreading education, differentiation and massifying of applications for individuals. At the present time, learning any subject is up to the tip of the fingers of an individual without depending on a school building with four walls or on certain time frame.

When literature and practices are examined regarding the freedom of individuals to receive education, the emphasis on "openness" stands out. The most striking example of this is the spread of Open Educational Resources (OERs), Open Educational Practices (OEPs) or Massive Open Online Courses (MOOCs) [1]. As such, the European Commission has increased the support of scientific research for the creation, use and implementation of Open Educational Resources as well as Massive Open Online Courses. Indeed, in this context, there have been many initiatives in Europe in the fields, which act as the driving force to transform teaching and learning at all levels, such as creative thinking, adult education, higher education, language teaching, occupational life, social inclusion, employability, multiculturalism, etc. [2]. As an umbrella term, Open Education (OE) can be defined as an education presentation form which aims expanding the number of participants; facilitates access; mostly based on digital technologies; customizable; enables both formal and informal education; provides access to courses, contents, support, evaluation and certification which respond to different needs [1], [3].

This flexibility in the access of individuals to education has created some requirements. When individuals get outside of the stereotype of the formal education and receive education on what they want at different levels of education (certificate, diploma, etc.), they get in need of proving their participation and experience [4]. Traditional educational institutions were monopolizing the learning certification and other stakeholders (student-teacher) did not have right to speak about it. Today, this situation is changing slowly with the development of technology [5]. However, individuals' activity records, scores or completion documents from different learning systems become isolated from each other and are not equivalent, and as a result, records of past education cannot be accessed in a proper way. Today, the number and diversity of institutions offering e-learning facilities and learning platforms offered by these institutions is increasing. Therefore, this rapid increase requires standardization of data of learning. In e-learning environments, the keeping of the data related to the students means the keeping records of the activities that the students have realized while learning. The data obtained from students' performance on quiz and assignments form a reference point for the evaluation and development of participation and performance [4].

The concept of distance education that provides flexible access to education has led to e-learning, online learning, or mobile learning as it supports its educational environments with digital technologies. In fact, it has had taken a part in the literature as u-learning (Ubiquitous learning), with the motto as education for everyone, everywhere, every time. However, as mentioned above, one of the necessities of flexible access to education is individuals' proof of participation and experience, while the other is the "security" in u-learning environments. These two needs arising as a result of the flexibility provided by technology in education (perhaps some other future needs) are also trying to be solved by technology. It is useful to give brief information about this technology, which is called blockchain technology and which is being called together with cryptocurrency.

Blockchain technology is known as a distributed database or an open ledger [6], [7]. All transactions or digital activities are carried out and shared among stakeholders. Compared to existing records of third-parties, the most important difference is that the blockchain is a fully distributed ledger that does not use a central authority. Each participant in the network has an exact copy of the ledger and all parties validate the chain updates [6], [8]. Bitcoin and Ethereum, the most important platforms that constitute more than $60 \%$ of the cryptocurrency market [9] provide transaction validity without a central authority by using blockchain technology. Blockchain technology has recently been aimed at providing much more privacy and security, especially using peer-to-peer (P2P) networks, and it is important to develop decentralized topologies.

In this study, it was aimed that the digital certificates that individuals receive as a result of their success or participation in e-learning environments can be verified by using blockchain technology. Hence, it is useful at this point to give some information about the blockchain technology that comes out for a different use and its use in education.

1. Distributed and Immutability: Today, the basic logic of Bitcoin, which attracts the attention of many people, is based on using blockchain technology to access all events on the network through nodes in the network and to monitor these events with a distributed consensus. Ledger entries are stored as time-stamped, immutable blocks. To ensure the security and consistency of ledger entries, nodes in the network compete with each other to solve a mathematical problem known as Proof of Work and add new blocks to the ledger. These nodes are called miners, and the first solver is rewarded. The processing power required to solve this mathematical problem makes it more difficult to rewrite blocks [4]. These features of blockchain 
technology guarantee the immutableness and permanence of the data added to the blockchain. Thus, this feature of the technology will be very suitable for the storage of educational data.

2. Smart contracts: Programs that can autonomously run on the blockchain under certain conditions are called as smart contracts. Any programmable process, flow, or protocol can be converted into a smart contract. When the requirements specified in the contracts are fulfilled or not, the necessary actions are taken automatically and the contract is executed. Depending on the requirements, smart contracts can be used to record data on the blockchain, and it would be great benefit by allowing the integration with existing systems used in the field of education.

Today, the fact that students are enrolled in different learning systems reveals the problem of storing separate repetitive data in a disjointed form. Even sometimes, individuals register for these education environments and do not continue. Sometimes, very little data such as names and surnames can be stored in these systems. But even such a small amount of data brings a cost and work power. Blockchain technology can be used to solve these and similar problems. Another benefit of the blockchain is that it should provide solution for the challenges of privacy, security and access control when sharing learning records with third parties [4].

\section{RELATED WORKS}

While the studies on the blockchain technology are still very new, reflections of these on the education are at the beginning of the age of crawling. Therefore, some of these few studies of the field are briefly summarized below.

One of the studies recommends different Learning Management Systems (LMS), Learning Record Stores (LRS), a block-chain-based approach for connecting learning data between institutions and organizations. Thus, it is tried to take advantage of the blockchain technology's ability to provide consistency, usability, immutableness, security, privacy and access control of learning data. The features of the proposed system can be listed as follows: "Distributed Consensus and Immutableness"; "Smart Contract Based Privacy, Security and Access Control" and "Single Ledger, Multiple Participants [4].

Based on the learning outcomes, a study in which educational-purpose blockchain technology is addressed used this technology and an automatic assessment software as a learning tool based on the university's graduation condition index and professional certification. Qualitative and quantitative assessed grades, process and evidences, name of course, name of learning output (graduation condition indicator) and credit of course, etc., are saved to the block. In the evaluation of the students' achievement, the transformation towards the post-employment qualification evaluations is completed and the curriculum is continuously developed by sending a curriculum to evaluate the difficulties facing student success [5].

Another study describes a new block-based architecture that takes security and privacy into account for u-learning environments. With this architecture, a secure learning system based on cooperation in decentralized topology is designed [6].

This postgraduate dissertation study addresses some problems that centralized e-learning platforms may encounter and emphasizes the importance of decentralized access control in solving these problems. In this context, a model proposal for decentralized access systems is presented. In the realization of this model, blockchain structure was utilized. Thus, it is argued that the integrity, correctness, deniability, and traceability of e-learning sources can be achieved. The mean response time was used as a metric when evaluating the proposed model. The two different network environments (such as the Local Area Network (LAN) and the Cloud Web Service (i.e. Amazon Web Service)) are compared. It is stated that LAN environment represents the most appropriate condition and the cloud environment represents the real situation in the real world. The average response time in the LAN environment is faster (about 1.5 times) than in the cloud environment, but when the number of customers is large, the difference in average response time between these two environments becomes insignificant [10].

CHiLO is a decentralized learning system that uses e-books for the needs of individuals to learn, train and practice at their own pace throughout their lives. In this work which developed CHiLO, the property rights of the block proprietors are provided to create an e-book by using the blockchain, combining the posts on the SNS and paying in virtual currency [11]

\section{OBJECTIVES AND SCOPE OF APPLICATION}

In this study, it is aimed to verify digital certificates given to the participants at the Turkish stage of the International Informatics and Computational Thinking event by using Ethereum Blockchain based smart contract. This event was created with the aim of teaching students of all ages about computer science and computational thinking. The first event held in Lithuania in 2004, while Turkey has been included in 2014 [12]. 35 thousand students in Turkey and more than 2 million students worldwide have participated in this event in 2017. The tasks in the event were transmitted to the students in Turkey via using exam module of the Moodle Learning Management System.

Although there are other certification tools available for Moodle (Accredible, Simple Certificate, etc.), some of them are paid and most of them are not compatible with current Moodle versions. It is also understood that only one of these tools (Accredible) has benefited from the public, private key feature of blockchain technology (see Figure 1). There were no examples of the use of smart contracts 
in the certificate tools examined. However, in learning management systems the use of blockchain technology and smart contract can be subject to many different usage possibilities not only certificates and badges but also SCORM tracking, user access and authorization, storing attendance, course information, and success grades [13]. The usage of smart contracts can eliminate the user intervention and allow the transactions to be performed automatically. With this study, it is planned to make an application about the use of smart contracts in a learning management system and to give an example for the researchers who are thinking about working in this issue in the future.

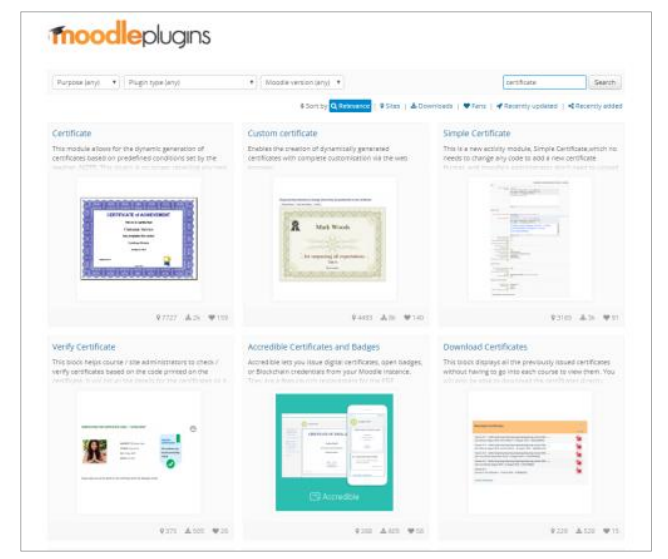

Figure 1. Moodle Certificate Plugins

For the purpose of this study, first a smart contract was developed in which the certificate information could be stored on the Ethereum blockchain and could be check for control purposes if necessary. Then the certificate module developed by the researcher in 2014 which uses block structure in the Moodle Learning Management System was updated and then provided to work in accordance with the smart contract in the Ethereum blockchain. Despite the fact that there are many different blockchain technologies that support smart contracts, the reasons to prefer the Ethereum Blockchain are usage by a large community, possibility of quick access to solutions to possible mistakes, presentation of an extensive API support and library of web3.js or web3.php (Ethereum for PHP) which is compatible with PHP based Moodle. This library makes it possible to perform operations on the Ethereum Blockchain using PHP or JavaScript language

\section{MOODLE LEARNING MANAGEMENT SYSTEM}

An institution needs a system to track learners who benefit from the educational service it offers. This system is usually a "Learning Management System". As is known, there are many paid and open source Learning Management Systems. Moodle is the most known of Open Source Learning Management Systems. Moodle is often preferred by many amateur or professional people or institutions, because of its features such as plugins and themes offered its users, easy installation and extensive documentation. Moodle provides students, teachers and administrators with almost all the tools needed to perform a program or course remotely. In addition, since it has plugins, blocks and modules, it can work either with many internal or external applications or services. Various plugins added to Moodle allow new blocks to be opened in the Moodle interface [14], [15]. The block plugin allows two types of configuration: global and local. A system administrator can configure the plugin globally thus can apply school policy to learning objects. When the local configuration is used, the instructor can set the sharing options for each course separately [15].

Once the block plugin is added, it can be accessed from all the main pages of Moodle (an open source learning management system). Blocks also make it possible for instructors with less technical skills to benefit from the system. Blocks allow the instructor to make use of the possibilities offered by the block without leaving the course environment [15]. Another feature of the block plugins is that the user can turn on or off this plugin if $s /$ he wants. A plugin tool can also be used by others [16]. Blocks that are likely to come up in a typical Moodle course can be calendar, external RSS feeds, course description, translator, participants, messages, etc. [17], [18]. Other blocks that can contribute to the learning environment can also be added to Moodle [18]. For example, the OpenSocial Moodle plugin allows the teacher to add a 'widget area' to the Moodle course page, to specify a set of widgets, and to select the widget layout on the Moodle page [14]. A block with different interfaces for the students and the teaching staff may be presented as another example for the identification, evaluation and support of university students with reading difficulties [18]. As can be seen from the sample applications, in Moodle, one of the most convenient ways to access external resources in a limited environment, such as a course, or in the entire Moodle without going out of the system is to use block structure [19]. The Moodle learning management system developed with the PHP programming language allows retrieving the information needed for data sharing with external systems and adding new information. The block structure is preferred as the most appropriate solution when working with external applications, since the Moodle system does not pose any problem in terms of its functioning.

\section{ETHEREUM BLOCKCHAIN}

Ethereum, launched in 2013 as an idea by Vitalik Buterin, became operational in 2015. It is mentioned that in 2014 while Buterin was 19 years old, Ethereum was raised to $\$ 18$ Million in just 42 days. Users are encouraged to contribute to Ethereum service which is a programmable blockchain [20]. Ethereum uses blockchain technology, like other cryptocurrencies. The feature that separates Ethereum from other cryptocurrencies is that it allows the development and execution of "smart contracts" and "distributed autonomous applications-DApps." These applications and smart contracts are developed with a programming language called "Solidity". The code written in Solidity is compiled and converted to bytecode and sent to the Ethereum blockchain as a Smart Contract [21]. Smart 
contracts and applications on the blockchain run on the Ethereum Virtual Machine (EVM). Operation of smart contracts on the blockchain and approval of the transaction bring costs such as contract size in bytecode, amount of data sent, and transaction fees. These costs are shown as Ether or Gas as sub-unit, during the dispatch and operation of the smart contract [22]. The development of smart contracts or distributed autonomous applications on real blockchains can lead to huge financial losses in possible coding errors. Therefore, it would be appropriate first to test locally/personally and then to test against all possible scenarios in the test blockchains such as Ropsten, Kovan, and Rinkeby and then send to the Ethereum blockchain. Applications sent to these networks, called Testnet, can be tested in all dimensions with any number of participants without any cost involved.

\section{IMPLEMENTATIONS}

The application development process of this study, which aims to verify digital certificates given to the participants by using Ethereum blockchain based smart contract, are explained below.

\subsection{Installation of Personal Ethereum Blockchain Tool}

To develop a smart contract on the Ethereum blockchain, Ganache, a Personal Ethereal blockchain application, was first installed and configured to run at http://localhost:8545. As shown in Figure 2, Ganache contains 10 accounts with 100 ethers as default. If desired, this number of accounts and the amount of Ethereum owned can be changed. These accounts can be used to send and receive Ethereum transactions, or to make operations on smart contracts. Ganache blockchain can also provide miner approval by forming a block for each process. Thus, it is not necessary to wait the approval of the transactions. However, smart contracts or transactions on this application disappear as soon as the application is closed. Therefore, all transactions must be repeated.

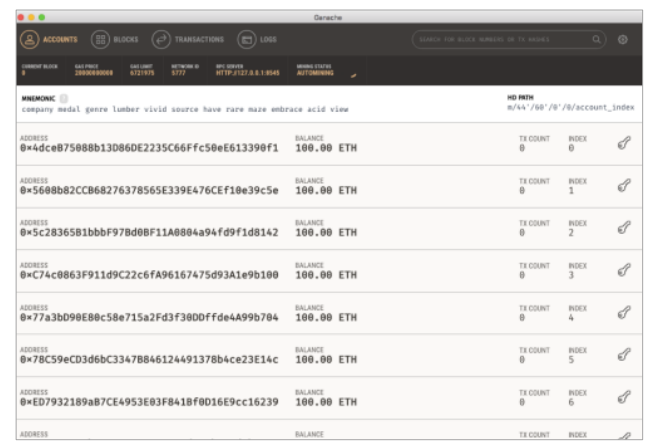

Figure 2. Ganache, Personal Blockchain For Ethereum

\subsection{Development of Smart Contract}

In order to write Ethereum-based smart contracts, a development environment (IDE) of Solidity language is needed. There are many development environments supported with user interface and command prompt to work with Solidity language. These environments include Remix (see Figure 3), Truffle and Parity as examples.

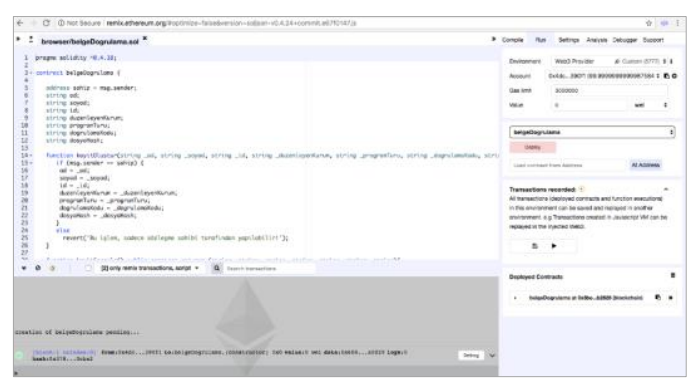

Figure 3. Remix Solidity IDE

Theoretically, a notepad-like application is sufficient for writing smart contracts in Solidity. However, it becomes necessary to use such development environments since both observing coding errors during writing the code and the Ethereum account is need to send the smart contract to the blockchain. Remix can work in concert with Ethereum blockchain applications such as Ganache, Truffle or Parity running on localhost. As shown in Figure 4, Metamask Ethereum wallet, which can be installed as an add-on on browsers such as Chrome or Firefox, can also be used with Remix. Thus, a smart contract written on the Remix platform can be sent to the test network or to the actual Ethereum blockchain, either through an account or wallet that has appropriate amount of Ethereum.

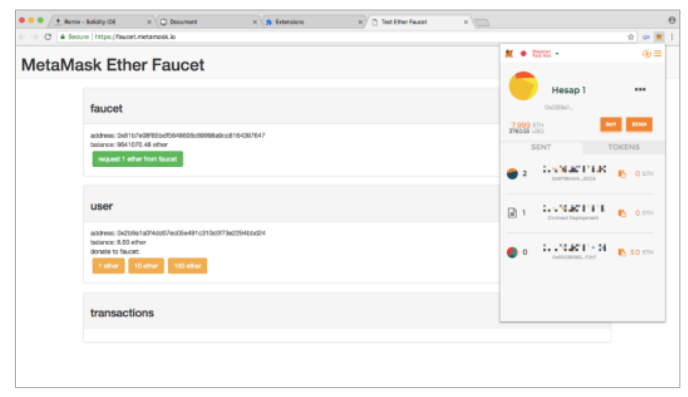

Figure 4. Metamask Ethereum Wallet

In this study, first Remix, which is a web-based IDE for developing smart contract, was used with Ganache. After the basic smart contract was developed, the contract development process was completed using Ropsten Ethereum Test Network and Parity Platform in order to better reflect the real Ethereum blockchain.

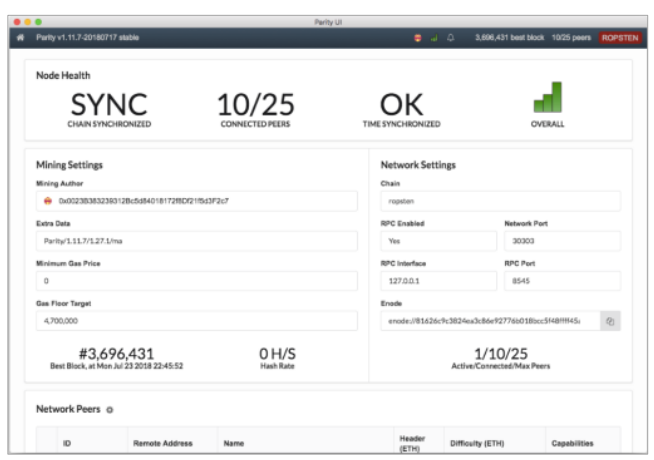

Figure 5. Parity UI Dashboard 
As an Ethereum Virtual Machine and Blockchain client, Parity (see Figure 5) runs through Terminal/Command Prompt in Windows, Linux and Mac operating systems and connects to Ethereum Main Network or test networks such as Ropsten, Kovan, and Rinkeby, thus enables developers to make real-time operations on blockchain.

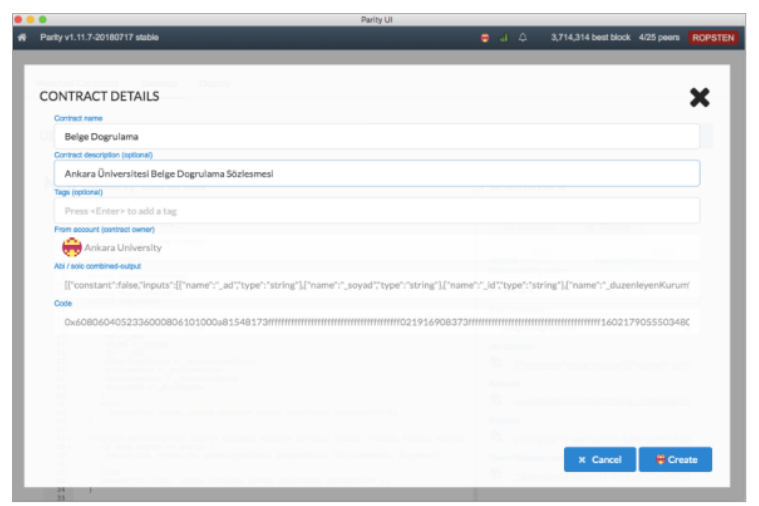

Figure 6. Parity UI Smart Contract Details

In addition, through the Parity UI (see Figure 6) named interface, smart contract development and sending it to blockchain, accounting and wallet transactions can be done through a single application.

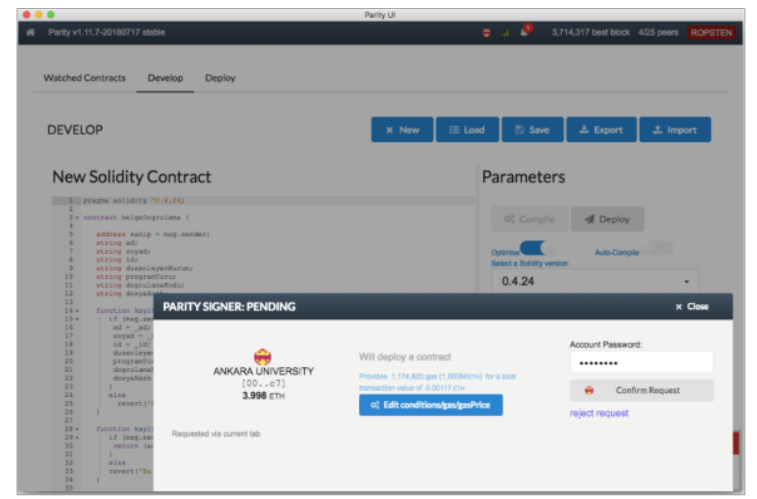

Figure 7. Parity UI Smart Contract Deployment

The smart contract, developed with Remix and then sent to the Ethereum Ropsten Test Network through the Parity UI application (see Figure 7), consists of two main functions. First function is to write the name, surname, identity information of the participant, the institution issuing the certificate, the document authentication code and the md5 hash value of the document which is obtained from the Moodle, on the Ethereum blockchain sending from only the permitted Ethereum account. The other function works by using the document authentication code specified on the certificate to verify the participant's digital certificate and to call the transaction hash of the record previously created in the blockchain and to retrieve the information of this transaction (see Figure 8).

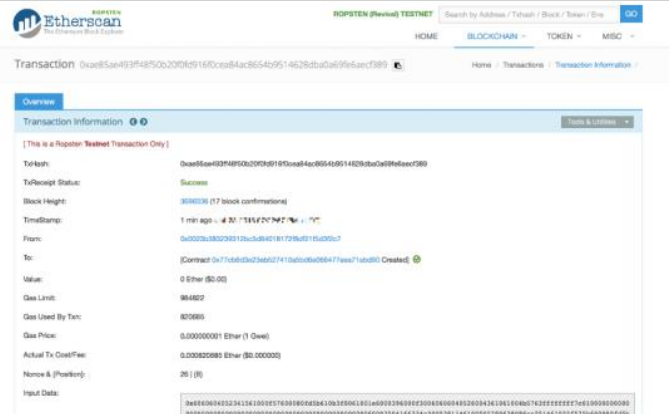

Figure 8. Transaction information of smart contract

\subsection{Updating the Certificate Block in Moodle Learning Management System}

One of the easiest ways to develop an application that can work with Moodle is to take advantage of the block feature. Moodle blocks can be used on a site-wide basis or on a course basis. It can also be turned off and on in terms of the users' roles, completion and viewing certain activities, getting certain scores from exams or assignments. The Digital Certificate Block developed by the researcher in 2014 enables students who have completed the International Informatics and Computational Thinking Event to be able to download their digital certificates using the Moodle exam module. In the developed certificate module, when the participant's first and last name information is obtained from Moodle and it is allowed to download in password-protected PDF format. In this study, the previously developed block structure was updated and used. In the certificate block, Web3.php library was used to send information about the institution and the certificate to the Ethereum smart contract. Web3 library, is used to make interaction between programming languages such as PHP, ASPNET, Javascript and so on, and the Ethereum Blockchain.

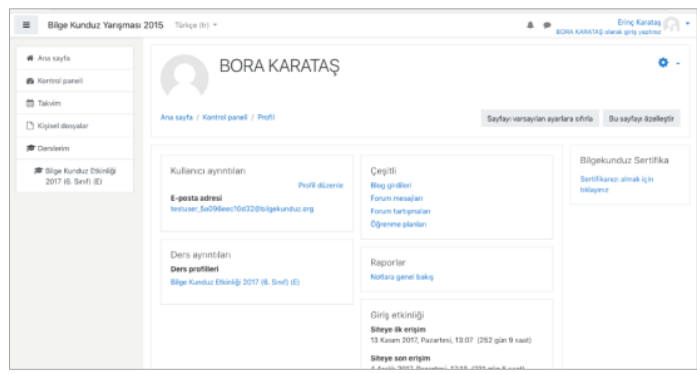

Figure 9. Student Profile Page (Before)

As shown in Figure 9, when students click on the link in the Certification Block to download their certificate, information of candidate, institution and file are registered into the Ethereum block chain by running a smart contract. Once the registration is complete, the certificate (see Figure 10) becomes available for download and the document control code generated uniquely and the transaction hash value of the process are written into the information fields created in the profile page of the student. (see Figure 11) 


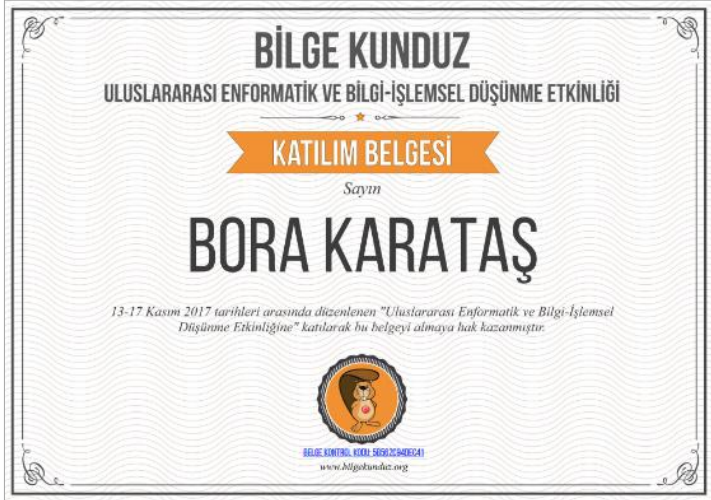

Figure 10. Student Participation Certificate

It is not possible to change the values written in these fields. If the student wishes to re-download the certificate, the process information in the profile field is checked and the smart contract is not allowed to run again if the process is found on the chain.

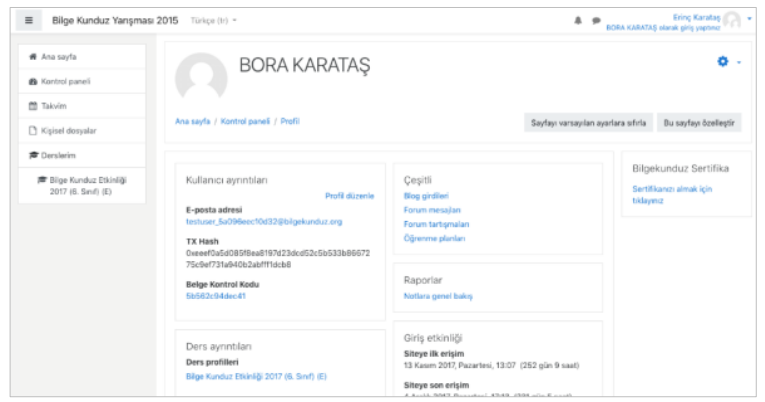

Figure 11. Student Profile Page (After)

As shown in Figure 12, a document verification page, which works in concert with the Moodle system, has been prepared so that the validity of the generated digital certificate can be controlled by 3rd parties. If the transaction information of the control code is found in the Moodle database, after the document control code on the digital certificate is entered into this page, the data stored in the blockchain is fetched through smart contract and the authenticity of the document is proved.

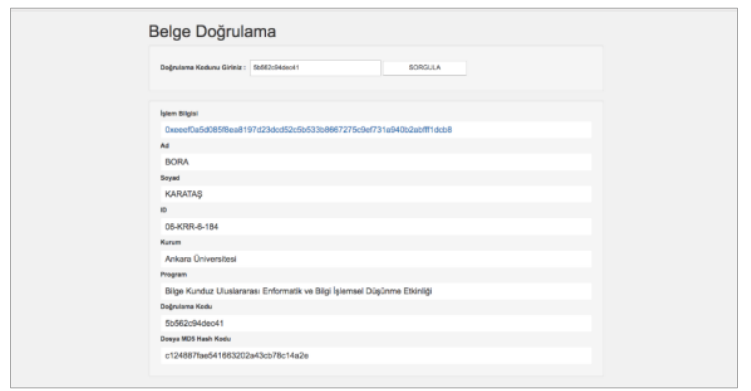

Figure 12. Document Verification Page

\section{LIMITATIONS}

The example used to illustrate the described approach was deployed in a concrete scenario. Of course there are some limitations of this scenario. This study is limited to the Turkish stage of the 'International Informatics and
Computational Thinking' event, Moodle Learning Management System, and Ethereum Blockchain.

\section{CONCLUSION}

Blockchain technology, which was originally mentioned along with Bitcoin and other crypto coins, is seen as a revolutionary technology in the near future in almost every field such as finance to engineering, education to health. It is possible to compare the present state of blockchain technology to the Internet in the 1990s. With regard to this technology, which is still in its infancy, there are a lot of field work, especially in the finance sector and computer science; we can say that we are at the beginning of the road, especially with respect to studies conducted in the field of education.

This study, which aimes to verify digital certificates given to the participants at the Turkish stage of the International Informatics and Computational Thinking event by using Ethereum Blockchain based on smart contract, is thought to be beneficial in that the use of the Moodle. As it is in this study, it is considered to offer an alternative approach for digitally producing and verifying the certificates required to be given to the participants of the programs opened in distance education or continuing education centers.

The data stability and permanence features of blockchain technology will be very suitable for the storing of educational data. For example if the universities in our country hold the records in the student information systems on the blockchain, an unchangeable and reliable common pool of data for grade equivalence, horizontal-vertical transitions between programs, admission to graduate programs and graduation information will be provided to access.

In future studies, it is thought that keeping the participant data and Scorm activities directly on the blockchain in Moodle and similar learning management systems will also solve the problem of cost and work power resulting from the separate storage of their repetitive data. Another benefit of the blockchain is that it produces a solution to the challenges of privacy, security and access control when sharing learning records with third parties, as noted above. As a result, it is thought that it will be very useful to record data on the block chain depending on the desired conditions through intelligent contracts, and to enable integration with existing systems used in education field by this feature.

\section{REFERENCES}

[1] C. Holotescu, G. Grosseck, "Towards a MOOC-related Strategy in Romania", BRAIN - Broad Research in Artificial Intelligence and Neuroscience, 9, 99-109, 2018.

[2] European Parliament. Committee on Culture and Education (Rapporteur Cătălin Sorin Ivan), Report on new technologies and open educational resources. Retrieved from http://www.europarl.europa.eu/sides/getDoc.do?pubRef=- 
//EP//TEXT+ REPORT+A7-2014-0249+0+DOC+XML+V0//EN, 25 March 2014.

[3] A. Inamorato dos Santos, Y. Punie, J.C. Mũnoz, Opening up Education: A Support Framework for Higher Education Institutions (No. JRC101436). Directorate Growth \& Innovation and JRC-Seville, Joint Research Centre, 2016.

[4] P. Ocheja, B. Flanagan, H. Ogata, "Connecting decentralized learning records: a blockchain based learning analytics platform", In Proceedings of the 8th International Conference on Learning Analytics and Knowledge, ACM, 265-269, 2018.

[5] B. Duan, Y. Zhong, D. Liu, (2017, "Education application of blockchain technology: learning outcome and meta-diploma", In Parallel and Distributed Systems (ICPADS), 2017 IEEE 23rd International Conference on, IEEE, 814-817, December 2017.

[6] R. Bdiwi, C. de Runz, S. Faiz, A. A. Cherif, "Towards a New Ubiquitous Learning Environment Based on Blockchain Technology", In Advanced Learning Technologies (ICALT), 2017 IEEE 17th International Conference, 101-102, 2017.

[7] Christidis, K., \& Devetsikiotis, M., "Blockchains and smart contracts for the internet of things", IEEE Access, 4, 2292-2303, 2016.

[8] G. W. Peters, E. Panayi, "Understanding modern banking ledgers through blockchain technologies: Future of transaction processing and smart contracts on the internet of Money", Banking Beyond Banks and Money, 239-278, Springer, Cham, 2016.

[9] İnternet: Coinmarketcap, Cryptocurrency market capitalizations, https: //coinmarketcap.com, 05.062018.

[10] S. Ma, Using blockchain to build decentralized access control in a peer-to-peer e-learning platform. Doctoral dissertation, University of Saskatchewan, 2018.

[11] M. Hori, S. Ono, K. Miyashita, S. Kobayashi, H. Miyahara, T. Kita T. Yamada, K. Yamaji, "Learning system based on decentralized learning model using blockchain and SNS", CSEDU 2018 . Proceedings of the 10th International Conference on Computer Supported Education, Volume 1 (Code 135926), Funchal, Madeira, Portugal, 183-190, 15-17 March, 2018.
[12] İnternet: Bilgekunduz, International Informatics and Computational Thinking Event, http://www.bilgekunduz.org/english, 07.06.2018.

[13] M. Turkanović, M. Hölbl, K. Košič, M. Heričko, A. Kamišalić, "EduCTX: A blockchain-based higher education credit platform", IEEE Access, 6, 5112-5127, 2018

[14] S. Govaerts, K. Verbert, E. Bogdanov, E. Isaksson, D. Dahrendorf, C. Ullrich, D. Gillet, Lessons Learned from the Development of the ROLE PLE Framework. In Responsive Open Learning Environments, Springer, Cham, 185-217, 2015.

[15] S. Tomić, V. Paunović, K. Zimmer, "Searching and exposing learning objects from Moodle: The ODS experience", Bulletin of the IEEE Technical Committee on Learning Technology, 17(1-2), 2015.

[16] T. Terefe, Simple date handling in Moodle: assignment and course daterollover, 2014

[17] Ž. Knežević, "Some Features of Moodle for English for Specific Purposes", Journal of Teaching English for Specific and Academic Purposes, 5(3), 467-481, 2017.

[18] C. Mejía Corredor, R. Fábregatb Gesa, D. Salas Álvarez, "Integration of a framework with a learning management system for detection, assessment and assistance of university students with reading difficulties", Revista EAN, (79), 98-115, 2015.

[19] Y. Gülhabar, H. Ilgaz, "Premise of Learning Analytics for Educational Context: Through Concept to Practice", Bilişim Teknolojileri Dergisi, 7(3), 12-20, 2014

[20] John M. Newman," Innovation policy for cloud-computing contracts", Research Handbook on Digital Transformations, Editors: F. Xavier Olleros and Majlinda Zhegu, Edward Elgar Publishing, 2016

[21] V. Gatteschi, F. Lamberti, C. Demartini, C. Pranteda, V. Santamaría, "Blockchain and Smart Contracts for Insurance: Is the Technology Mature Enough?”, Future Internet, 10(2), 20, 2018.

[22] İnternet: V. Buterin, A next-generation smart contract and decentralized application platform (2014), https://github.com/ethereum/wiki/wiki/White-Paper, 07.06 .2018 